\title{
Posttraumatic Intracerebral Haemorrhage of a Patient with Inhibitor Positive Hemophilia A: A Case Report
}

Pusem Patir ${ }^{\star}$, Osman Butun, Mustafa Duran, Fatos Dilan Koseoglu, Nur Akad Soyer, Fahri Sahin and Guray Saydam

Ege University, Bornova, Izmir, Turkey

*Corresponding author: Pusem Patir, Medical Doctor, Ege University, Bornova, Izmir, Turkey, Tel: 90232311 10 10; E-mail: pusemp@yahoo.com

Received date: Dec 21, 2015, Accepted date: Jan 27, 2016, Publication date: Jan 31, 2016

Copyright: ( 2016 Patir P, et al. This is an open-access article distributed under the terms of the Creative Commons Attribution License, which permits unrestricted use, distribution, and reproduction in any medium, provided the original author and source are credited.

\begin{abstract}
Treatment of hemaophilia patients with inhibitor has been difficult situation especially in emergency rooms. Here, we report the successful treatment of a patient with inhibitor positive severe hemophilia A hospitalized due to intracerebral haemorrhage after traffic accident.
\end{abstract}

Keywords: Hemophilia; Inhibitor; Cerebral haemorrhage

\section{Introduction}

The development of inhibitor is more common in patients with hemophilia A than in those with hemophilia B. Factor VIII inhibitors have been reported in approximately 25 to 30 percent of patients with severe hemophilia A [1-3]. Both host and product factors influence the likelihood of inhibitor formation. Research continues to define the best predictors of inhibitor formation, as well as methods to decrease or prevent formation. Bypassing products have included activated prothrombin complex concentrates (aPCC) and recombinant human factor VIIa (rFVIIa). Here we report the successful treatment of a patient with inhibitor positive severe hemophilia A suffer from intracerebral haemorrhage after traffic accident.

\section{Case Report}

A 36-year-old Caucasion male with inhibitor positive severe hemophilia A presented with an unconsciousness to emergency room after heavy traffic accident. The patient is monitored regularly under prophylactic aPCC treatment twice per week at a dose of $25 \mathrm{IU} / \mathrm{kg}$ in our adult hemophilia outpatient unit since 2009. In history, the patient had a traffic accident in a car eight hours ago and although there were no signs of bleeding, aPCC was administered at a dose of $25 \mathrm{IU} / \mathrm{kg}$ once to stop any potential bleeding by himself. But, later, deteriorations have occurred in his conscious status. His physical examination revealed no evidence of haematoma formation on the body. His conscious status was observed as stupor and no orientation and cooperation. Other system findings were normal. There were no external findings of bleeding and no focal neurological deficits. Cranial and whole-body computed tomographies (CT) were urgently performed in terms of intracranial and intraabdominal haemorrhage. Cranial CT revealed subcutaneous haematoma of the left parietal scalp, haemorrhage in left lateral ventricle and $3^{\text {rd }}$ ventricle, subarachnoid haemorrhage, left insular lobe haematoma about $9 \mathrm{~mm}$ diameter and 5 $\mathrm{mm}$ shift towards the right of midline structures (Figure 1a and 1b). aPCC was administered immediately at a dose of $100 \mathrm{IU} / \mathrm{kg}$ every 12 hours. The neurosurgery consultation was conducted because of that shift and neurological signs and it was not planned to operate because of positivity of his inhibitor status. And also, there was high bleeding risk for removal of the haematoma. Progression in haemorrhage
(Figure 2) was observed in control cranial CT and no objective clinical response to current medical therapy, so his treatment was switched promptly to rFVIIa at a dose of $90 \mu \mathrm{g} / \mathrm{kg}$ every 2 hours. He had a prolonged activated partial thromboplastin time (aPTT) as 44.6 seconds, and his inhibitor level was measured as $5.9 \mathrm{BU} / \mathrm{ml}$. The medical condition of patient improved day by day and returned completely to normal by the fourth day of rFVIIa treatment. The dosage of rFVIIa was adjusted to $90 \mu \mathrm{g} / \mathrm{kg}$ every 3 hour, then every 4 hour and 6 hour, each lasting 4 days, for a total treatment period took 2 weeks. Regression of haematoma was detected in serial follow-up cranial CT (Figure 3). He continued to have prophylaxis with aPCC at a dose of $25 \mathrm{IU} / \mathrm{kg}$ three times per week as indicated. After 1 month, control cranial CT confirmed complete disappearance of the haemorrhage (Figure 4).

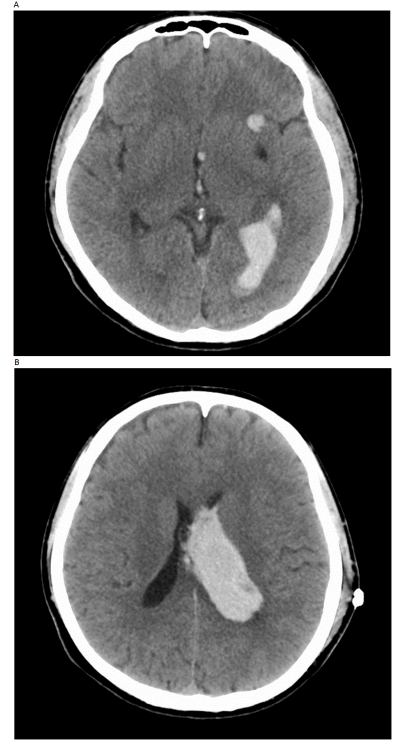

Figure 1: The CT of the head, showing an intracerebral (a) and intraventricle (b) haemorrhage at first arrival. 


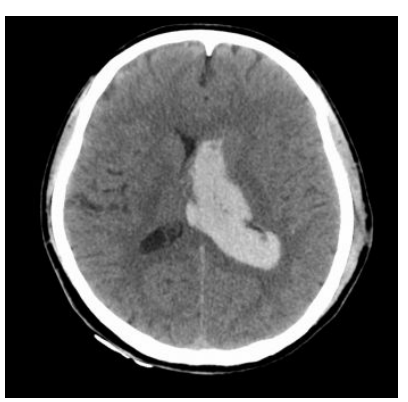

Figure 2: The CT of the head, showing a progression in haemorrhage under aPCC treatment.

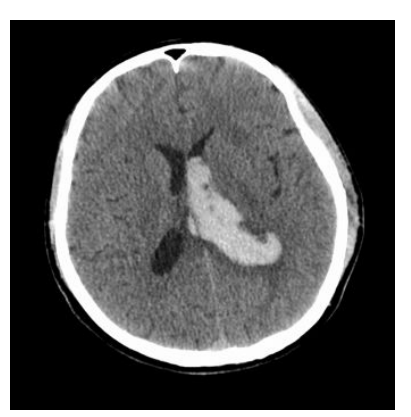

Figure 3: The CT of the head, showing a regression in haemorrhage under rFVIIa treatment.

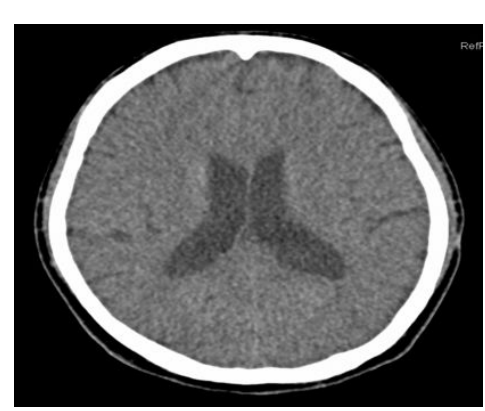

Figure 4: The CT of the head, showing complete resorption of the haemorrhage at time of last control.

\section{Discussion}

Central nervous system bleeding occurs in about $2.7 \%$ of patients with hemophilia A $[4,5]$. Although $\mathrm{ICH}$ is rare in comparison with other sites of bleeding, it is one of the most dangerous and lifethreatening incidents in haemophilia [6]. ICH can occur in individuals of all ages, spontaneously or after trauma.

In our case, ICH occured after traffic accident. Also our case had a inhibitor positive severe hemophilia A and used prophylactic aPCC treatment twice per week at a dose of $25 \mathrm{IU} / \mathrm{kg}$. According to the literature; trauma, severe disease, presence of an inhibitor, age over 50 years, and in some cases human immunodeficiency virus (HIV) infection were defined as risk factors for IHC but also implemented that prophylaxis is associated with reduction of ICH risk $[7,8]$.

ICH can occur immediately after trauma or as a delayed complication days to weeks later. Importantly, delayed ICH can occur up to three to four weeks after trauma. ICH usually presents with headache, vomiting, and lethargy; seizures are also common. However, some episodes are clinically silent and detected incidentally on brain imaging [9]. Patients with head and neck injuries should receive immediate factor replacement and neuroimaging should be performed; however, infusion of factor should not be delayed while awaiting neuroimaging. In our case, aPCC was administered immediately at a dose of $25 \mathrm{IU} / \mathrm{kg}$ by himself but he neglected to go to the emergency quickly. This case demonstrates that the hemophilia patients should be raised awareness and educated by physicians about dangerous and lifethreatening incidents.

The specific sites of ICH were approximately one-third were intracerebral, one-third subdural, and the remainder subarachnoid, epidural, or unspecified [8,9]. Our case had multiple haemorrhage areas such as intracerebral, intraventricles, subarachnoid causing the shift which we managed promptly with rFVIIa. Decompression surgery was not considered by the neurosurgeon because of bleeding could not be controlled. Inhibitor positive hemophilia patients may require treatment with bypassing agents for bleeding episodes. Bypassing products have included aPCC and rFVIIa. Bypassing agents are administered to inhibitor positive hemophilia patients as safe and effective in bleeding events $[10,11]$. In our case, progression in haemorrhage was detected under aPCC treatment and his treatment switched urgently to the rFVIIa. Turkish Society of Hematology Hemophilia Treatment Guide recommends rFVIIa at a dose of 90 $\mu \mathrm{g} / \mathrm{kg}$ every 2 hours for 24 hours regardless of the age, the inhibitor level and the severity of factor VIII deficiency in major bleeding in inhibitor positive hemophilia A patients. Then the dose range is increased from 3-4 to 6-8 hours according to objective clinical response. The duration of treatment can last up to 14 days. Although different doses of rFVIIa $(350 \mu \mathrm{g} / \mathrm{kg}$ of rFVIIa was administered in neurosurgery [12]) have been reported in the literature, the usual dose of rFVIIa for treatment of bleeding is 90 to $120 \mu \mathrm{g} / \mathrm{kg}$ at two-three hour intervals until hemostasis is achieved, with further dosing and lengthening of the interval based upon the patient's clinical situations [13]. Our patient started to improve by the fourth day of rFVIIa with a dose of $90 \mu \mathrm{g} / \mathrm{kg}$ every 2 hours treatment. However, the optimal dosing regimen of rFVIIa is controversial in CNS bleeding.

\section{Conclusion}

rFVIIa is an effective therapy for the treatment of ICH in hemophilia patients with inhibitors, its optimal use with respect to safety and efficacy requires further clinical study. Hemophilia A patients should be closely monitored in terms of late haemorrhagic events after trauma.

\section{Patient Consent}

Informed consent was obtained for publication of anonymized patient information.

\section{Conflict of Interest}

Authors declare no conflict of interests for this article. 
Citation: Patir P, Butun O, Duran M, Koseoglu FD, Soyer NA, et al. (2016) Posttraumatic Intracerebral Haemorrhage of a Patient with Inhibitor Positive Hemophilia A: A Case Report . J Blood Disord Transfus 7: 338. doi:10.4172/2155-9864.1000338

Page 3 of 3

\section{Author Contributions}

All authors equally contributed to this paper with conception and literature review, and critical revision and editing, and final approval of the final version.

\section{References}

1. Hoyer LW, Scandella D (1994) Factor VIII inhibitors: structure and function in autoantibody and hemophilia A patients. Semin Hematol 31: $1-5$.

2. Lusher JM, Arkin S, Abildgaard CF, Schwartz RS (1993) Recombinant factor VIII for the treatment of previously untreated patients with hemophilia A. Safety, efficacy, and development of inhibitors. Kogenate Previously Untreated Patient Study Group. N Engl J Med 328: 453-459.

3. Rasi V, Ikkala E (1990) Haemophiliacs with factor VIII inhibitors in Finland: prevalence, incidence and outcome. Br J Haematol 76: 369-371.

4. Eyster ME, Gill FM, Blatt PM, Hilgartner MW, Ballard JO, et al. (1978) Central nervous system bleeding in hemophiliacs. Blood 51: 1179-1188.

5. de Tezanos Pinto M, Fernandez J, Perez Bianco PR (1992) Update of 156 episodes of central nervous system bleeding in hemophiliacs. below Haemostasis 22: 259-267.

6. Franchini M, Mannucci PM (2013) Hemophilia A in the third millennium. Blood Rev 27: 179-184.

7. Witmer C, Presley R, Kulkarni R, Soucie JM, Manno CS, et al. (2011) Associations between intracranial haemorrhage and prescribed prophylaxis in a large cohort of haemophilia patients in the United States. Br J Haematol 152: 211-216.

8. Nuss R, Soucie JM, Evatt B, Hemophilia Surveillance System Project Investigators (2001) Changes in the occurrence of and risk factors for hemophilia-associated intracranial haemorrhage. Am J Hematol 68 : 37-42.

9. Nelson MD Jr, Maeder MA, Usner D, Mitchell WG, Fenstermacher MJ, et al. (1999) Prevalence and incidence of intracranial haemorrhage in a population of children with haemophilia. The Hemophilia Growth and Development Study. Haemophilia 5: 306-312.

10. Ingerslev J (2000) Efficacy and safety of recombinant factor VIIa in the prophylaxis of bleeding in various surgical procedures in hemophilic patients with factor VIII and factor IX inhibitors. Semin Thromb Hemost 26: 425-432.

11. Ingerslev J, Feldstedt M, Sindet-Pedersen S (1991) Control of haemostasis with recombinant factor VIIa in patient with inhibitor to factor VIII. Lancet 338: 831-832.

12. Banov L, Pavanello M, Piattelli G, Disma N, Severino M, et al. (2014) Successful urgent neurosugery management with rFVIIa mega doses in a child with hemophilia A and high titre inhibitor. Blood Coagul Fibrinolysis 25: 518-521.

13. Kempton CL, White GC 2nd (2009) How we treat a hemophilia A patient with a factor VIII inhibitor. Blood 113: 11-17. 